\title{
Predictors of outcome in patients with degenerative cervical spondylotic myelopathy undergoing surgical treatment: results of a systematic review
}

\author{
Lindsay A. Tetreault - Alina Karpova • \\ Michael G. Fehlings
}

Received: 30 October 2012/Revised: 3 December 2012/ Accepted: 3 January 2013/Published online: 6 February 2013

(C) The Author(s) 2013. This article is published with open access at Springerlink.com

\begin{abstract}
Purpose To conduct a systematic review of the literature to determine important clinical predictors of surgical outcome in patients with cervical spondylotic myelopathy (CSM).

Methods A literature search was performed using MEDLINE, MEDLINE in Process, EMBASE and Cochrane Database of Systematic Reviews. Selected articles were evaluated using a 14-point modified SIGN scale and classified as either poor $(<7)$, good (7-9) or excellent (10-14) quality of evidence. For each study, the association between various clinical factors and surgical outcome, evaluated by the (modified) Japanese Orthopaedic Association scale (mJOA/JOA), Nurick score or other measures, was defined. The results from the EXCELLENT studies were compared to the combined results from the EXCELLENT and GOOD studies which were compared to the results from all the studies.

Results The initial search yielded 1,677 citations. Ninetyone of these articles, including three translated from Japanese, met the inclusion and exclusion criteria and were graded. Of these, 16 were excellent, 38 were good and 37 were poor quality. Based on the excellent studies alone, a longer duration of symptoms was associated with a poorer outcome evaluated on both the mJOA/JOA scale and Nurick score. A more severe baseline score was related with a worse outcome only on the mJOA/JOA scale. Based on the GOOD and EXCELLENT studies, duration of symptoms and baseline severity score were consistent predictors of
\end{abstract}

L. A. Tetreault · A. Karpova · M. G. Fehlings ( $₫)$

Krembil Neuroscience Center, Toronto Western Hospital,

University of Toronto, 399 Bathurst St. 4WW449,

Toronto, ON M5T 2S8, Canada

e-mail: Michael.fehlings@uhn.on.ca
mJOA/JOA, but not Nurick. Age was an insignificant predictor of outcome on any of the functional outcomes considered.

Conclusion The most important predictors of outcome were preoperative severity and duration of symptoms. This review also identified many other valuable predictors including signs, symptoms, comorbidities and smoking status.

Keywords Cervical spondylotic myelopathy · Clinical predictors - Surgical outcome Systematic review

\section{Introduction}

Cervical spondylotic myelopathy (CSM) is the most common cause of spinal cord dysfunction worldwide. The disease is caused by the degeneration of various components of the vertebra, including the vertebral body, the intervertebral disk, the supporting ligaments and the facet joints [1]. Static factors, including the protrusion of osteophytic spurs (spondylosis), disk desiccation, ossification of the posterior longitudinal ligament (OPLL) and hypertrophy of the ligamentum flavum, may lead to the narrowing of the spinal canal and to cord compression [2]. Longstanding compression of the spinal cord can result in irreversible damage including demyelination and necrosis of the gray matter. The onset of CSM is generally insidious and progresses in a stepwise fashion [3, 4]. Upon diagnosis of symptomatic CSM, a physician often recommends surgical treatment to decompress the spinal cord [5]. Surgery has proven to be an effective intervention for the full range of myelopathy severity [6].

Given that CSM is a prevalent cause of spinal cord injury, and since surgery is often an appropriate intervention, 
it would be useful to identify the most important predictors of surgical outcome. Prediction is a valuable tool in a clinical setting. Knowing a patient's surgical outcome can help determine which patients are most likely to benefit from surgery and help assess their degree of functional improvement [7]. This allows surgeons to provide valuable prognostic information to concerned patients, helping to manage expectations, as well as implement and direct appropriate treatment programs.

Holly et al. [8] conducted a similar systematic review of the literature and found that the most common predictors of surgical outcome for patients with CSM were age, duration of symptoms and severity of myelopathy. These three clinical factors are most frequently reported in the literature. Controversy still remains as to the significance, strength and direction of the relationship between surgical outcome and age, duration of symptoms and baseline severity.

The objective of this paper is to conduct a comprehensive literature search to determine the most important clinical predictors of outcome in surgical CSM-patients. This paper will address whether age, duration of symptoms, baseline severity score are indeed predictors and will also examine other clinical factors including comorbidities, smoking status, signs and symptoms to determine their predictive value.

\section{Materials and methods}

A literature search was performed using MEDLINE, MEDLINE in Process, EMBASE and Cochrane Central Register of Controlled Trials. The keywords used for the search were Cervical Spondylotic Myelopathy AND Surgery or Postoperative AND Prediction/Prognosis AND observational studies. The search was limited to humans, aged 18 years or older. The total number of citations found for this review was 1,677 .

Articles were included if they were observational studies on patients $>18$ years with degenerative cervical myelopathy, treated surgically and followed postoperatively. Articles must have either directly or indirectly assessed the ability of a clinical factor to predict surgical outcome. Articles were eliminated if they were review articles or opinions; studies on patients with traumatic spinal cord injuries, thoracic myelopathy, radiculopathy, or nondegenerative cervical myelopathy; studies assessing only radiographic factors as predictors and studies that used complications as an outcome measure. Articles that were not in English or Japanese were excluded. Japanese articles were translated by Dr. Iwasaki and were included in the analysis.
All 1,677 abstracts and titles were reviewed independently by two authors (LAT, AK) and were sorted based on pre-determined inclusion and exclusion criteria. Figure 1 displays the search and review process in detail. Ninetyone articles were included. Three of these were translated from Japanese to English. Each article was assessed for quality with respect to methodology and overall structure. Several rating scales were examined, including Altman [9], Hayden et al. [10], and the Scottish Inter-Collegiate Guidelines Network (SIGN) scale for prognostic studies [11]. A modified version of the SIGN scale was used to rate the articles.

A modified version of the SIGN scoring system was implemented in a systematic review published by KalsiRyan and Verrier [12]. Since the incidence of spinal cord injury is comparatively low, high quality research in this field is challenging. Studies often have small sample sizes with no opportunity for blinded assessment and randomization. Kalsi-Ryan and Verrier modified SIGN so that it was more specific to the nature of literature they were reviewing. We selected the modified SIGN system and further altered it to increase its applicability to literature reporting clinical predictors of surgical outcome in patients with CSM. Questions 15 and 16 were changed from dichotomous scoring to trichotomous scoring as studies may vary greatly in quality of statistical analysis, methodology and bias elimination (Table 1). It was arbitrarily decided that an article whose score was $<7$ would be classified as POOR, 7-9 as GOOD and 10-14 as EXCELLENT. The results from the EXCELLENT studies were compared to the combined results from the EXCELLENT and GOOD studies which were compared to the results from all the studies.

For each study, the association between various clinical factors and surgical outcome, evaluated by the (modified) Japanese Orthopaedic Association scale (mJOA/JOA), Nurick score or "other" measures, was extracted. A relationship between the outcome and predictor was defined as conditional, if it was significant for certain groups of patients but not others or using one statistical test, but not another.

\section{Results}

This review consisted of 37 POOR [13-49], 38 GOOD [50-87] and 16 EXCELLENT [88-103] articles (Table 2).

Fifteen of these studies controlled for confounding variables when looking at the association between outcome and age, duration of symptoms and baseline severity score. The outcome measure used in all EXCELLENT studies was either the Nurick or the mJOA/JOA, with one study commenting on both. 


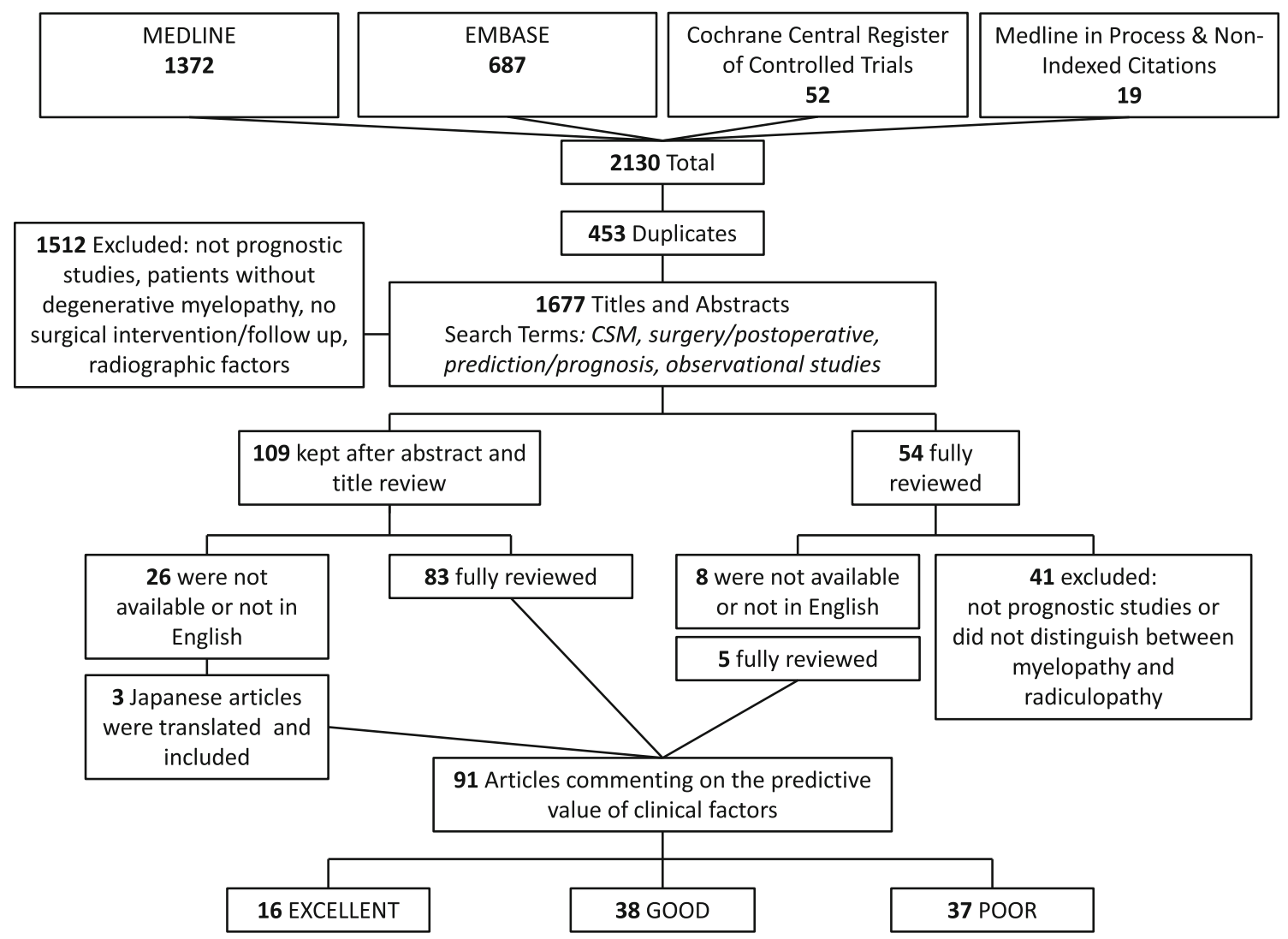

Fig. 1 Search strategy and detailed review process. CSM cervical spondylotic myelopathy

Table 1 Modified Scottish Inter-collegiate Guidelines Network (SIGN) used to rate all articles

\begin{tabular}{|c|c|c|c|}
\hline Checklist item original & $\begin{array}{l}\text { Original } \\
\text { scoring }\end{array}$ & $\begin{array}{l}\text { Dichotomous } \\
\text { scoring }\end{array}$ & Comments/interpretations \\
\hline $\begin{array}{l}\text { 1. The study addresses an appropriate and clearly } \\
\text { focused question }\end{array}$ & 6-point scale & $\begin{array}{l}\text { Yes }=1 \\
\text { No }=0\end{array}$ & \\
\hline $\begin{array}{l}\text { 2. The two groups being studied are selected from } \\
\text { source populations that are comparable in all } \\
\text { respects other than the factor under } \\
\text { investigation }\end{array}$ & 6-point scale & - & \\
\hline $\begin{array}{l}\text { 3. The study indicates how many people were asked } \\
\text { to take part did so, in each of the groups being } \\
\text { studied }\end{array}$ & 6-point scale & $\begin{array}{l}\text { Yes }=1 \\
\text { No }=0\end{array}$ & Retrospective studies receive a score of zero \\
\hline $\begin{array}{l}\text { 4. The likelihood that some eligible subjects } \\
\text { might have the outcome at the time of } \\
\text { enrolment is assessed and taken into account in } \\
\text { the analysis }\end{array}$ & 6-point scale & - & \\
\hline $\begin{array}{l}\text { 5. What percent (Did any) of individuals or clusters } \\
\text { recruited into each arm of the study dropped out } \\
\text { before the study was completed? }\end{array}$ & $\%$ & $\begin{array}{l}\text { Yes }=0 \\
\text { No }=1\end{array}$ & $\begin{array}{l}\text { Retrospective studies receive a score of zero unless } \\
\text { they commented on drop off rate }(>80 \%) \text {. } \\
\text { Prospective studies with a }>80 \% \text { follow-up } \\
\text { receive a } 1\end{array}$ \\
\hline $\begin{array}{l}\text { 6. Comparison is made between full participants } \\
\text { and those lost to follow-up, by exposure status }\end{array}$ & 6-point scale & - & \\
\hline 7. The outcomes are clearly defined & 6-point scale & $\begin{array}{l}\text { Yes }=1 \\
\text { No }=0\end{array}$ & \\
\hline $\begin{array}{l}\text { 8. The assessment of outcome is made blind to } \\
\text { exposure status }\end{array}$ & 6-point scale & - & \\
\hline
\end{tabular}


Table 1 continued

\begin{tabular}{|c|c|c|c|}
\hline Checklist item original & $\begin{array}{l}\text { Original } \\
\text { scoring }\end{array}$ & $\begin{array}{l}\text { Dichotomous } \\
\text { scoring }\end{array}$ & Comments/interpretations \\
\hline $\begin{array}{l}\text { 9. Where blinding was not possible, there is some } \\
\text { recognition that knowledge of exposure status } \\
\text { could have influenced the assessment of } \\
\text { outcome }\end{array}$ & 6-point scale & - & \\
\hline $\begin{array}{l}\text { 10. The measure of assessment of exposure is } \\
\text { reliable }\end{array}$ & 6-point scale & $\begin{array}{l}\text { Yes }=1 \\
\text { No }=0\end{array}$ & \\
\hline $\begin{array}{l}\text { 11. Evidence from other sources is used to } \\
\text { demonstrate that the method of outcome } \\
\text { assessment is valid and reliable }\end{array}$ & 6-point scale & $\begin{array}{l}\text { Yes }=1 \\
\text { No }=0\end{array}$ & \\
\hline $\begin{array}{l}\text { 12. Exposure level or prognostic factor is assessed } \\
\text { more than once }\end{array}$ & 6-point scale & $\begin{array}{l}\text { Yes }=1 \\
\text { No }=0\end{array}$ & \\
\hline $\begin{array}{l}\text { 13. The main potential confounders are identified } \\
\text { and taken into account in the design and analysis }\end{array}$ & 6-point scale & $\begin{array}{l}\text { Yes }=1 \\
\text { No }=0\end{array}$ & $\begin{array}{l}\text { The main confounders are age, duration of } \\
\text { symptoms and baseline severity score }\end{array}$ \\
\hline 14. Have confidence intervals been provided? & 6-point scale & $\begin{array}{l}\text { Yes }=1 \\
\text { No }=0\end{array}$ & $\begin{array}{l}\text { Have the results been reported using good statistical } \\
\text { methods? }\end{array}$ \\
\hline $\begin{array}{l}\text { 15. How well was the study done to minimize the } \\
\text { risk of bias or confounders, and to establish a } \\
\text { causal relationship between exposure and effect? }\end{array}$ & Code,+++ or - & $\begin{array}{l}\text { Yes }=1 \\
\text { No }=0\end{array}$ & $\begin{array}{l}\text { Trichotomous rating } \\
0=\text { poor } \\
1=\text { good } \\
2=\text { excellent }\end{array}$ \\
\hline $\begin{array}{l}\text { 16. Taking into account clinical considerations, your } \\
\text { evaluation of the methodology used, and the } \\
\text { statistical power of the study, are you certain that } \\
\text { the overall effect is due to the exposure being } \\
\text { investigated? }\end{array}$ & Yes/No & $\begin{array}{l}\text { Yes }=1 \\
\text { No }=0\end{array}$ & $\begin{array}{l}\text { Trichotomous rating } \\
0=\text { poor } \\
1=\text { good } \\
2=\text { excellent }\end{array}$ \\
\hline $\begin{array}{l}\text { 17. Are the results of this study directly applicable to } \\
\text { the patient group targeted in this guideline? }\end{array}$ & Yes/No & $\begin{array}{l}\text { Yes }=1 \\
\text { No }=0\end{array}$ & \\
\hline
\end{tabular}

Checklist items in bold are those removed from the original checklist

${ }^{\text {a }}$ Question 15: To score a perfect 2, the study must be a prospective study with no selection and recruitment bias, must have a follow-up rate $>80 \%$ and must have controlled for confounders. A prospective study that met some, but not all of this criteria scores a 1 . A retrospective study that has controlled for confounders also scores a 1. A highly biased retrospective or prospective study that has no control receives a score of 0

${ }^{\mathrm{b}}$ Question 16: A study has sufficient statistical power if, for every predictor evaluated, there are at least 10 participants. Based on the score in question 15, a study can either go up, go down one point or stay the same depending on whether its sample size meets this basic rule

\section{Duration of symptoms}

Thirteen articles evaluated duration of symptoms as a predictor of surgical outcome. Nine reported a negative, three a non-significant and one a conditional relationship. It is evident that outcome, assessed on both the mJOA/JOA and Nurick scale, is dependent on preoperative duration of symptoms as indicated by significantly more articles reporting a negative association than a non-significant association. The $R$ values for this negative relationship ranged from weak to strong [95] (Table 3).

Baseline severity score

Nine articles reported on the relationship between baseline severity score and surgical outcome. One article suggested a negative, seven a positive and one a non-significant association. All studies (7) that used JOA as the primary outcome measure demonstrated that more severe preoperative myelopathy is predictive of a worse outcome. When assessing this association on the Nurick scale, there was one article reporting a positive, one a negative and one an insignificant relationship, making it difficult to draw a conclusion as to the predictive value of preoperative severity on Nurick. One study recorded a strong $R$ value (0.61) for this positive association [95] (Table 3).

Age

All 16 articles explored the importance of age on surgical outcome. Six studies found a negative, eight a non-significant and two a conditional relationship. Breaking it down by scale, two articles reported a negative and two a nonassociation between age and Nurick. Four and six studies 


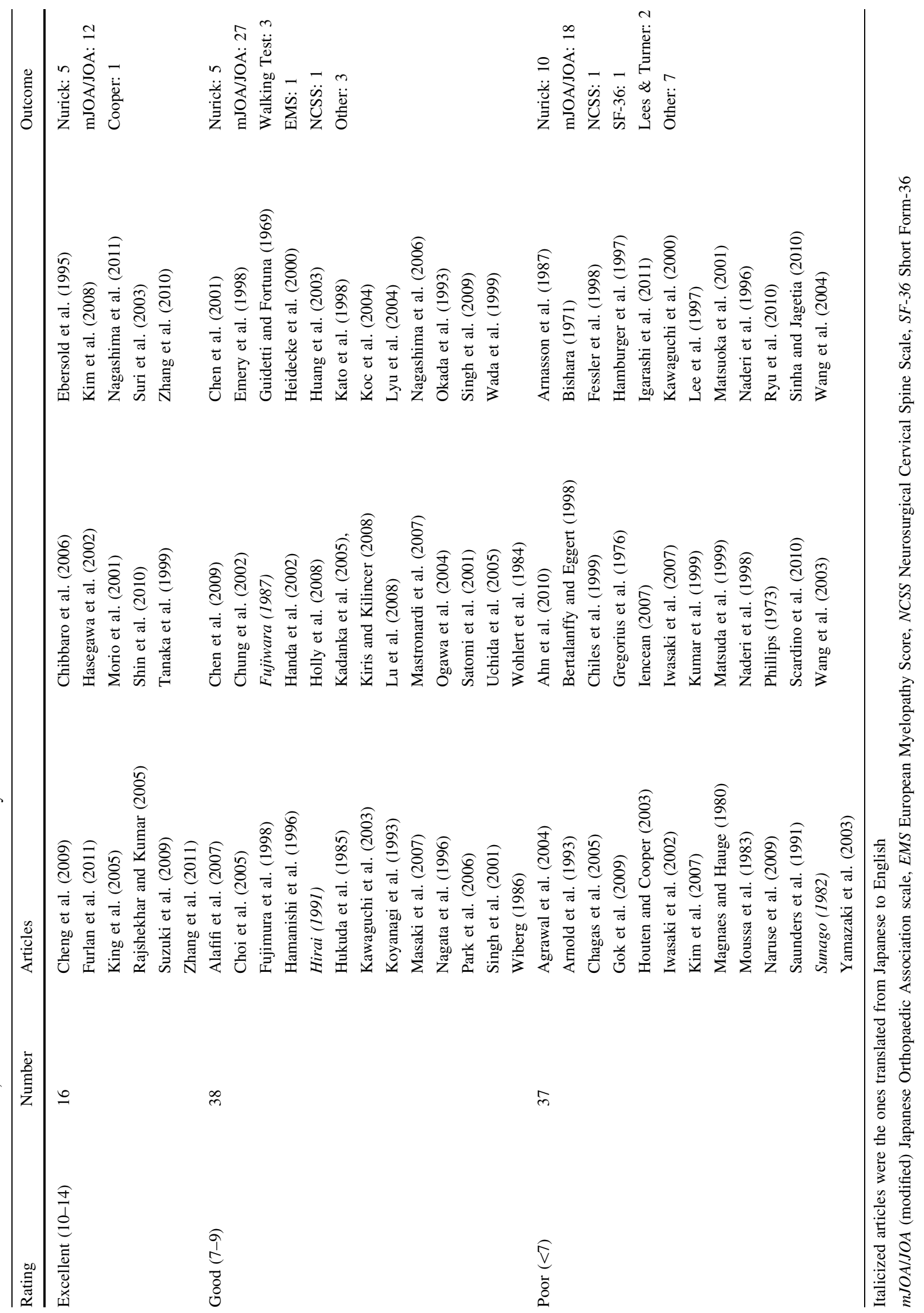




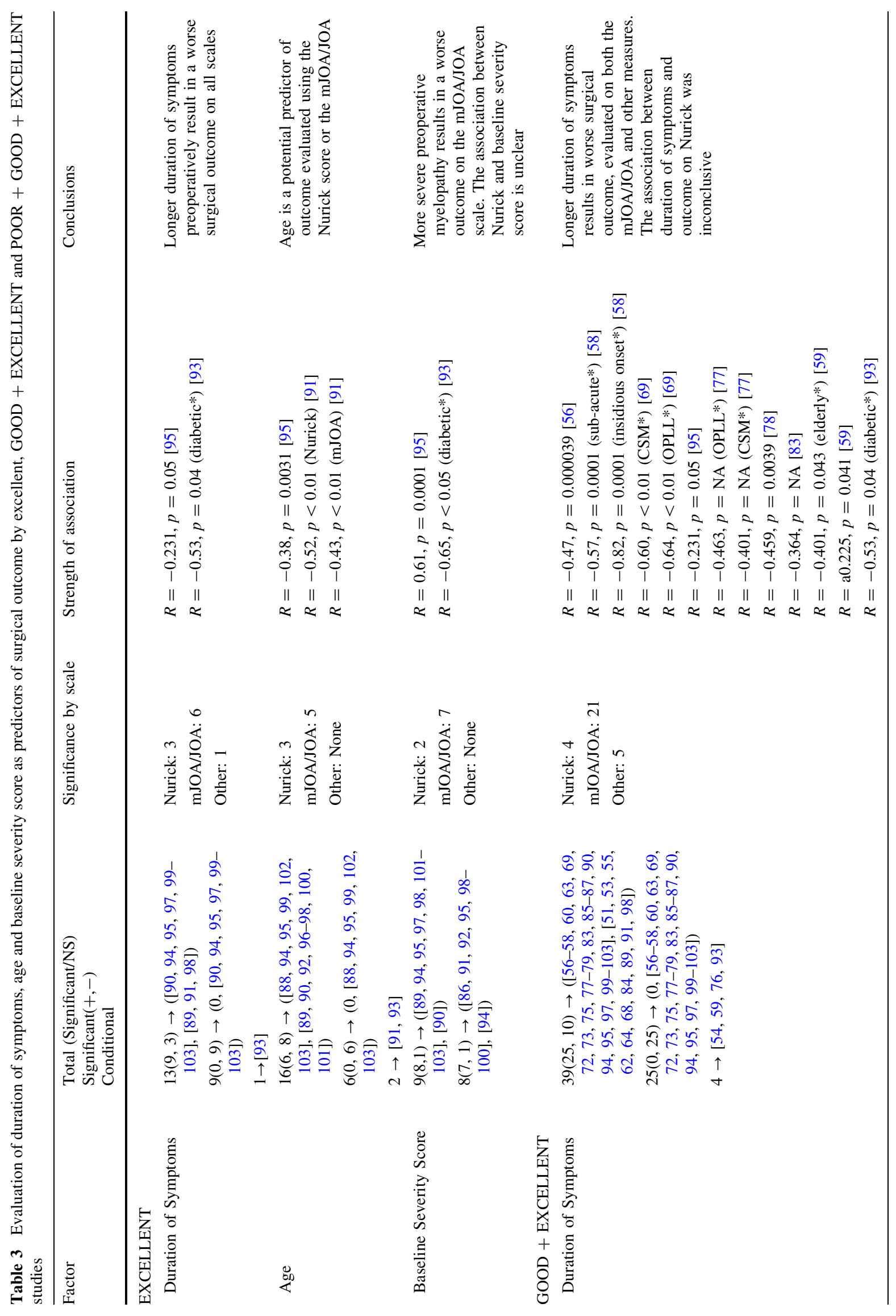




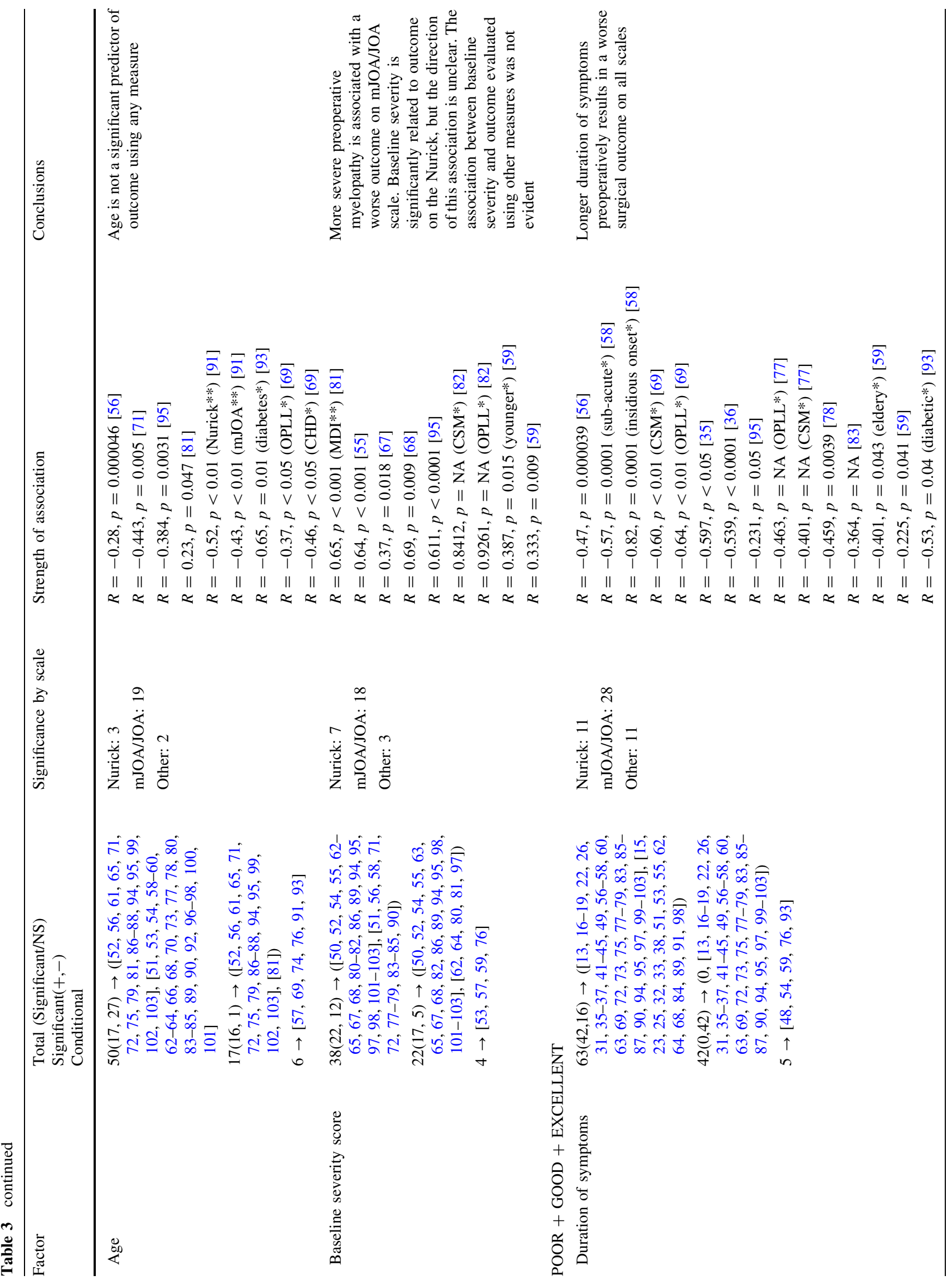




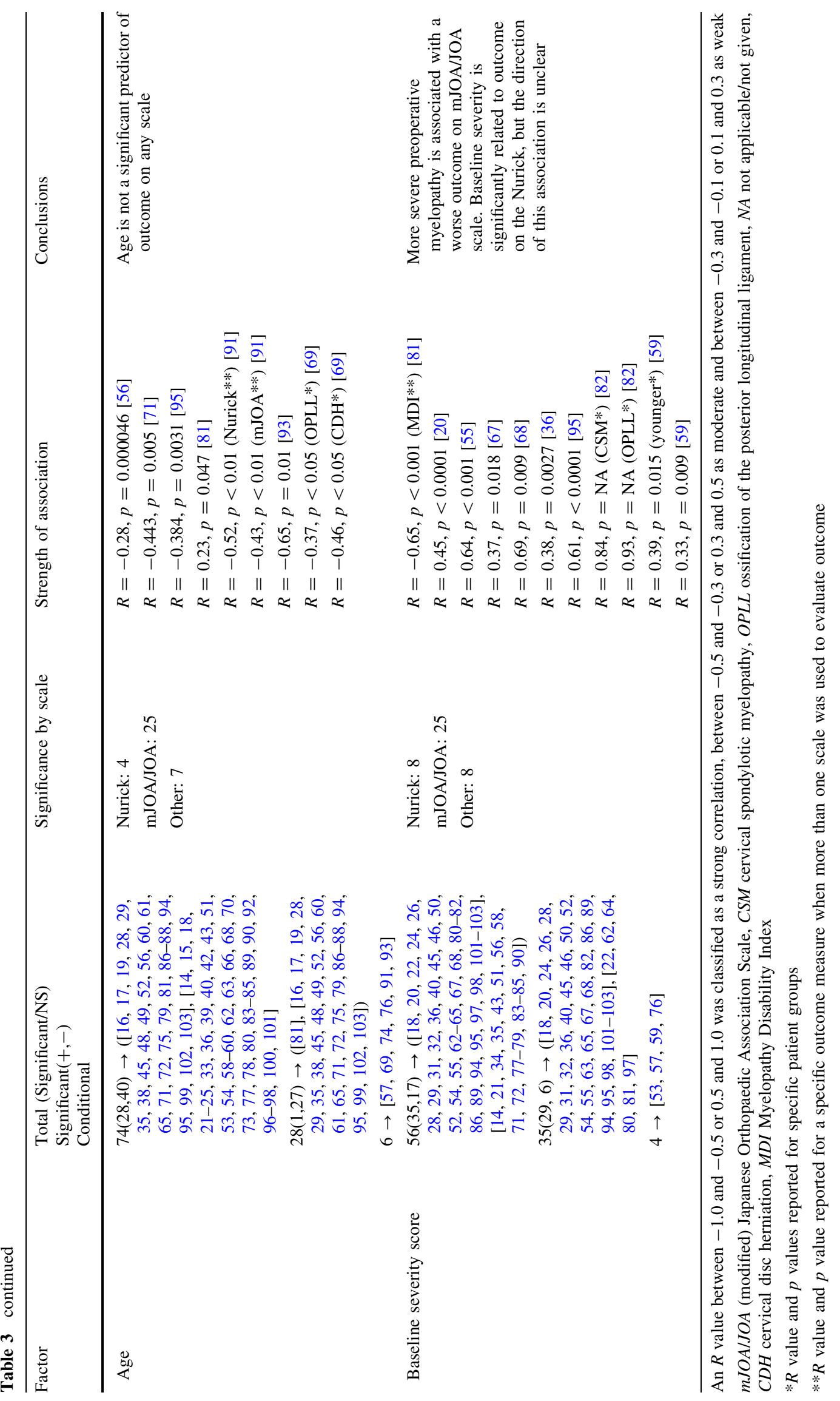


found a negative and a non-relationship, respectively, between age and JOA/mJOA. It is unclear as to the association between age and outcome evaluated by Nurick, but it is possible to suggest that age may not be predictive of outcome on the JOA/mJOA scale. The two conditional studies were not included in this count. Furlan et al. [91] found that age was a significant predictor of outcome on both scales using multiple regression, but not after dichotomizing the mJOA outcome. In addition, Kim et al. [93] suggested that age was an important predictor, but only in patients with diabetes. The $R$ values for this negative relationship ranged from moderate to strong (Table 3 ).

Most of the GOOD articles were not rated excellent due to flaws in their statistical analysis such as a lack of control for confounding variables. In contrast to the EXCELLENT studies, the GOOD studies used a wider variety of scales and measures to assess outcome such as the Cooper, neurosurgical cervical spine scale (NCSS), neurological assessments, questionnaires and evaluation of symptom improvement.

\section{Duration of symptoms}

Thirty-nine articles investigated duration of symptoms as a potential predictor of outcome. Twenty-five reported a negative, ten a non-significant and four a conditional relationship. It is evident that there is a significant negative association between duration of symptoms and outcome evaluated on both the JOA/mJOA scale and other measures: 22 versus 8 articles identified a negative versus a non-significant relationship. Using the Nurick scale, on the other hand, the results were inconclusive: four articles reported a negative and four a non-association. Inclusion of the conditional articles did not alter these results. The $R$ values for this negative relationship ranged from weak to strong (Table 3).

\section{Baseline severity score}

Thirty-eight studies assessed baseline severity score as a potential predictor of surgical outcome. Five reported a negative, 17 a positive, 12 a non-significant and 4 a conditional relationship. It is evident that outcome, evaluated by $\mathrm{mJOA} / \mathrm{JOA}$, is positively dependent on the baseline severity score: 15 papers suggested a positive association, while only 8 reported a non-significant relationship. It is hard to define the relationship between baseline score and Nurick score as two versus four papers reported negative versus positive associations. It is clear that baseline score is a significant predictor of Nurick, but the direction of the relationship is unclear. With respect to all the other outcome measures, two and three studies suggested a negative and a non-significant relationship, respectively.
The R-values of this association ranged from moderate to strong (Table 3).

Age

Fifty articles reported on age as a predictor of outcome. Sixteen identified a negative, one a positive, 27 a nonsignificant and 6 a conditional association between age and outcome. Age was not found to be a predictor of outcome, assessed using either the Nurick, mJOA/JOA or other measures. Two and 14 papers found age had a negative association with Nurick and JOA/mJOA, respectively. Five and 18 studies, on the other hand, reported no relationship with Nurick or JOA/mJOA, respectively. It is important to incorporate the conditional studies into this analysis, especially those that used JOA/mJOA as the primary outcome measure. Both Nagashima et al. and Ogawa et al. $[74,76]$ identified age as a significant predictor of outcome in more severe myelopathy groups, but not in moderate severity (10-12) groups. Furlan et al. [91] identified age as an important negative predictor using multiple regression, but not stepwise logistic regression. Finally, Koyanagi et al. [69] suggested that age was a significant predictor in patients with OPLL and CDH, but not CSM. Incorporating these results into our assessment of age as a predictor, we still conclude that it is an insignificant predictor. The $R$ values of the significant associations ranged from weak to strong (Table 3).

The POOR studies had significant flaws, including study design and poor statistical power and control. In addition, many of these studies used unreliable outcome measures to evaluate surgical improvement and suffered on their ratings as a result.

\section{Duration of symptoms}

Sixty-three articles explored duration of symptoms as a predictor of surgical outcome. Forty-two reported a negative, 16 a non-significant and 5 a conditional relationship. The results were clear for all outcome measures: a longer duration of symptoms was predictive of a worse outcome. The $R$ value of this association was reported in six studies and ranged from weak to strong (Table 3).

\section{Baseline severity score}

Fifty-six papers assessed baseline severity score as a predictor of outcome. Twenty-nine reported a positive, 17 a non-significant, 6 a negative and 4 a conditional association. Baseline severity score was a definite positive predictor of outcome assessed using the JOA/mJOA and other measures. Twenty-two versus ten papers reported a positive versus a non-significant association. The relationship 
between baseline severity score and Nurick was inconclusive: three papers identified as a negative, four a positive and two a non-significant association. As in the good/ excellent analysis, it is evident that preoperative severity is related to Nurick score, but the direction of this association is unclear. The $R$ value of this positive association was reported in six studies and ranged from moderate to strong (Table 3).

\section{Age}

Seventy-four studies commented on age as a potential predictor. Twenty-seven identified a negative, 1 a positive, 40 a non-significant and 6 a conditional association. Age was not a significant predictor of outcome, assessed using either the Nurick score or other measures. Nine papers reported a non-significant relationship between age and Nurick, whereas only four suggested a negative relationship. Without looking at the conditional associations, JOA/ mJOA was also not dependent on age as indicated by 25 articles reporting no relationship and 20 suggesting a negative one. Five articles identified a conditional association between age and $\mathrm{mJOA} / \mathrm{JOA}$. The results from these studies do not affect these conclusions. The $R$ values from studies that reported an association ranged from weak to moderate (Table 3).

\section{Other predictors}

Articles included in this review also explored the predictive value of other factors including gender, signs and symptoms, disease progression pattern and various comorbidities. The results from these studies are displayed in Table 4. There is no sufficient evidence in the literature to conclude that the presence of a particular sign or symptom or co-morbidity is predictive of outcome.

\section{Discussion}

This review compared the results from the EXCELLENT, GOOD + EXCELLENT and POOR + GOOD + EXCELLENT papers (Table 5).

One of the major findings of this review was that patients with a longer duration of symptoms and a more severe baseline score are more likely to have an unfavorable surgical result. The rationale behind this finding is that both severe and chronic, longstanding compression of the spinal cord may lead to irreversible damage due to demyelination and necrosis of the gray matter. Secondly, controversy exists in the literature as to the significance, strength and direction of the relationship between surgical outcome and age. Age was a non-significant predictor on all the scales when looking at the GOOD + EXCELLENT and the POOR + GOOD + EXCELLENT studies. When looking at only the higher quality studies (modified SIGN $\geq 10$ ), however, age went from a non-significant predictor to a potential predictor. Although most surgeons will not discriminate on the basis of age, they should be aware that the elderly are not able to translate neurological recovery to functional improvement as well as the younger population. Potential explanations for this discrepancy include: (1) the elderly experience age related changes in their spinal cord including a decrease in $\gamma$-motoneurons, number of anterior horn cells and number of myelinated fibers in the corticospinal tracts and posterior funiculus, (2) older patients are more likely to have unassociated comorbidities that may affect outcome or (3) the elderly may not be able to conduct all activities on a certain functional scale due to these comorbidities (e.g. walking time may be affected by osteoarthritis) [35, 75, 88, 92, 93]. Finally, our review determined that factors such as signs (hyperreflexia, leg spasticity and Babinski sign), symptoms (gait impairment, clumsy hands and numbness), comorbidities (diabetes and psychological issues), and smoking status do carry some predictive value. Physicians should progressively incorporate predictive modeling into their practices to provide valuable prognostic information to their patients and direct appropriate treatment programs. When evaluating a CSM patient's likely surgical outcome, the surgeon must weigh his/her preoperative severity, duration of symptoms and age accordingly while keeping in mind the ability of other factors to affect the outcome.

As shown in this review, results may differ depending on what scale is used to evaluate surgical outcome. This may be due to limitations in the scales rather than an indication of the actual association between the predictor and outcome. The Nurick score is a scale with lower sensitivity, it is graded out of five and is largely weighted towards lower limb function [104]. When outcome was assessed using the Nurick score, its association with various predictors was less conclusive. For example, duration of symptoms was significantly associated with Nurick score when looking at the EXCELLENT and the POOR + GOOD + EXCELLENT group, but was a questionable predictor in the GOOD + EXCELLENT group. In addition, in the GOOD + EXCELLENT and POOR + GOOD + EXCELLENT studies, there was a significant relationship between preoperative condition and Nurick, but the direction of the association was not evident. The articles that identified a negative association, however, had more biased samples: Gok et al., Huang et al. and Rajshekhar and Kumar [22, 62, 97] all had stricter inclusion criteria. On the other hand, the results were more definite when the outcome was evaluated on either the JOA or mJOA score: a longer duration of symptoms and a more 
Table 4 Other prognostic indicators of surgical outcome reported either by EXCELLENT, GOOD or POOR studies

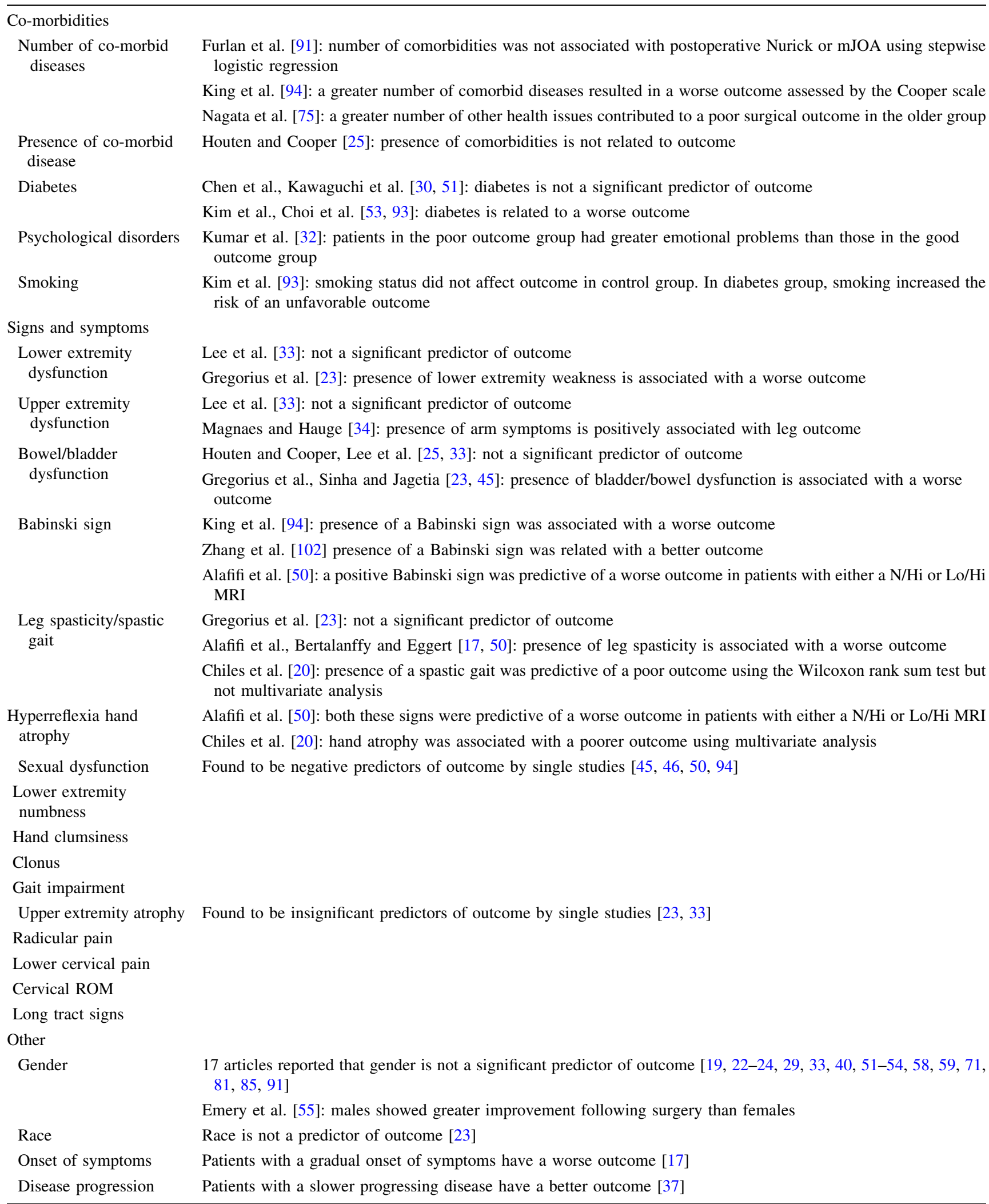

mJOA modified Japanese Orthopaedic scale, N/Hi normal/high, Lo/Hi low/high, MRI magnetic resonance imaging 
Table 5 Summary of results: percentages of articles reporting a negative, positive, non-significant or conditional association between surgical outcome and duration of symptoms, baseline severity score or age

\begin{tabular}{|c|c|c|c|c|}
\hline & Negative & Positive & Non-significant & Conditional \\
\hline \multicolumn{5}{|l|}{ Excellent } \\
\hline Duration of symptoms & $69 \%$ & NA & $23 \%$ & $8 \%$ \\
\hline Baseline severity score & $11 \%$ & $78 \%$ & $11 \%$ & NA \\
\hline Age & $37.5 \%$ & NA & $\mathbf{5 0} \%$ & $12.5 \%$ \\
\hline \multicolumn{5}{|l|}{ Good + excellent } \\
\hline Duration of symptoms & $65 \%$ & NA & $26 \%$ & $10 \%$ \\
\hline Baseline Severity Score & $13 \%$ & $45 \%$ & $31.5 \%$ & $10.5 \%$ \\
\hline Age & $32 \%$ & $2 \%$ & $54 \%$ & $12 \%$ \\
\hline \multicolumn{5}{|l|}{ Poor + good + excellent } \\
\hline Duration of symptoms & $67 \%$ & NA & $25 \%$ & $8 \%$ \\
\hline Baseline severity score & $11 \%$ & $52 \%$ & $30 \%$ & $7 \%$ \\
\hline Age & $36.5 \%$ & $1.5 \%$ & $54 \%$ & $8 \%$ \\
\hline
\end{tabular}

Bold values indicate the relationship between predictor and outcome with the highest percentage

severe baseline severity score were associated with a worse outcome. The mJOA and JOA are widely accepted standards for CSM assessment and separately evaluate lower and upper limb, sphincter and sensory function. Although JOA has been validated and shown to have high inter- and intra-rater reliability [105], its modified version has not.

In a research setting, when looking at a relationship between various factors and outcome, it is important to control for the confounders baseline severity score and duration of symptoms. When assessing statistical control in our review to rate the articles, we ensured that the studies controlled for age, duration of symptoms and baseline severity as these were identified as important predictors by Holly et al. [5]. According to this review, age may be a less important confounder. Few articles reported on the $R$ values for the significant associations between various clinical factors and outcome. This makes it difficult for clinicians and researchers to evaluate the strength of these correlations.

Holly et al. [5] indicated that the limitations of their review were that there were very few prospective studies, that many studies assessed the outcome using un-validated measures and that it was hard to analyze functional outcome due to the use of different scales between studies. Our study had much larger pool of articles and consisted of higher quality literature, including some prospective studies that evaluated outcome using the validated JOA scale or Nurick score. There was also a sufficient number of articles to compare predictors on the same scale. In addition, the differences in our methodology, including a comparison of results among the three groups, also allowed for the incorporation of quality assessment in the analysis. Since, the Japanese have had a substantial contribution to research in the field of spinal cord injury, including the creation of the JOA scale, we also translated all Japanese articles into English and incorporated them into our analysis. Finally, our systematic review differed from Holly et al.'s as it included a preliminary analysis of other predictors including signs and symptoms, comorbidities, gender and smoking status to determine their predictive value.

There are limitations to our study: (1) we did not separate studies based on length of follow-up time; (2) articles that dichotomized a predictor might have done it differently (e.g. age) and (3) some of the articles with relevant abstracts or titles were excluded because they were not available or in another language other than Japanese or English. Future systematic reviews should address these limitations to provide a completely unbiased evaluation of important predictors of outcome.

The results from this review should encourage further exploration in this area. Even though many studies have examined important predictors of surgical outcome in CSM, there still remains a lack of evidence in the form of high quality, prospective studies using validated outcome measures. A large prospective analysis is required to reemphasize the predictive value of duration of symptoms and baseline severity score, to settle the controversy surrounding age and to confirm that signs, symptoms and comorbidities do impact surgical results.

\section{Conflict of interest None.}

Open Access This article is distributed under the terms of the Creative Commons Attribution License which permits any use, distribution, and reproduction in any medium, provided the original author(s) and the source are credited. 


\section{References}

1. Tracy JA, Bartleson JD (2010) Cervical spondylotic myelopathy. Neurologist 16:176-187. doi:10.1097/NRL.0b013e3181da3a29

2. Baptiste DC, Fehlings MG (2006) Pathophysiology of cervical myelopathy. Spine J 6:190S-197S. doi:10.1016/j.spinee.2006. 04.024

3. Matz PG, Anderson PA, Holly LT, Groff MW, Heary RF, Kaiser MG, Mummaneni PV, Ryken TC, Choudhri TF, Vresilovic EJ, Resnick DK (2009) The natural history of cervical spondylotic myelopathy. J Neurosurg Spine 11:104-111. doi:10.3171/2009. 1.spine 08716

4. Emery SE (2001) Cervical spondylotic myelopathy: diagnosis and treatment. J Am Acad Orthop Surg 9:376-388

5. Holly LT, Matz PG, Anderson PA, Groff MW, Heary RF, Kaiser MG, Mummaneni PV, Ryken TC, Choudhri TF, Vresilovic EJ, Resnick DK (2009) Functional outcomes assessment for cervical degenerative disease. J Neurosurg Spine 11:238-244. doi: 10.3171/2009.2.spine08715

6. Fehlings MG, Arvin B (2009) Surgical management of cervical degenerative disease: the evidence related to indications, impact, and outcome. J Neurosurg Spine 11:97-100. doi:10.3171/2009. 5.spine 09210

7. Haynes RB, Sackett DL, Guyett GH, Tugwell P (2006) Clinical epidemiology: how to do clinical practice research. Lippincott Williams \& Wilkins, Philadelphia

8. Holly LT, Matz PG, Anderson PA, Groff MW, Heary RF, Kaiser MG, Mummaneni PV, Ryken TC, Choudhri TF, Vresilovic EJ, Resnick DK (2009) Clinical prognostic indicators of surgical outcome in cervical spondylotic myelopathy. J Neurosurg Spine 11:112-118. doi:10.3171/2009.1.spine08718

9. Altman DG (2001) Systematic reviews of evaluations of prognostic variables. BMJ 323:224-228

10. Hayden JA, Cote P, Bombardier C (2006) Evaluation of the quality of prognosis studies in systematic reviews. Ann Intern Med 144:427-437

11. Ahn NU, Ahn UM, Ipsen B, An HS (2007) Mechanical neck pain and cervicogenic headache. Neurosurgery 60:S21-S27

12. Kalsi-Ryan S, Verrier MC (2011) A synthesis of best evidence for the restoration of upper-extremity function in people with tetraplegia. Physiother Can 63(4):474-489

13. Agrawal D, Sharma BS, Gupta A, Mehta VS (2004) Efficacy and results of expansive laminoplasty in patients with severe cervical myelopathy due to cervical canal stenosis. Neurology India 52:54-58

14. Ahn J-S, Lee J-K, Kim B-K (2010) Prognostic factors that affect the surgical outcome of the laminoplasty in cervical spondylotic myelopathy. Clin 2:98-104

15. Arnasson O, Carlsson CA, Pellettieri L (1987) Surgical and conservative treatment of cervical spondylotic radiculopathy and myelopathy. Acta Neurochir (Wien) 84:48-53

16. Arnold H, Feldmann U, Missler U (1993) Chronic spondylogenic cervical myelopathy. A critical evaluation of surgical treatment after early and long-term follow-up. Neurosurg Rev 16:105-109

17. Bertalanffy H, Eggert HR (1988) Clinical long-term results of anterior discectomy without fusion for treatment of cervical radiculopathy and myelopathy. A follow-up of 164 cases. Acta Neurochir (Wien) 90:127-135

18. Bishara SN (1971) The posterior operation in treatment of cervical spondylosis with myelopathy: a long-term follow-up study. J Neurol Neurosurg Psychiatry 34:393-398

19. Chagas H, Domingues F, Aversa A, Vidal Fonseca AL, de Souza JM (2005) Cervical spondylotic myelopathy: 10 years of prospective outcome analysis of anterior decompression and fusion. Surg Neurol 64 Suppl 1:S1:30-35 [discussion S31: 35-36]

20. Chiles IBW, Leonard MA, Choudhri HF, Cooper PR (1999) Cervical spondylotic myelopathy: patterns of neurological deficit and recovery after anterior cervical decompression. Neurosurgery 44:762-770

21. Fessler RG, Steck JC, Giovanini MA (1998) Anterior cervical corpectomy for cervical spondylotic myelopathy. Neurosurgery 43:257-267

22. Gok B, McLoughlin GS, Sciubba DM, McGirt MJ, Chaichana KL, Wolinsky J-P, Bydon A, Gokaslan ZL, Witham TF (2009) Surgical management of cervical spondylotic myelopathy with laminectomy and instrumented fusion. Neurol Res 31:10971101

23. Gregorius FK, Estrin T, Crandall PH (1976) Cervical spondylotic radiculopathy and myelopathy. A long-term follow-up study. Arch Neurol 33:618-625

24. Hamburger C, Buttner A, Uhl E (1997) The cross-sectional area of the cervical spinal canal in patients with cervical spondylotic myelopathy: correlation of preoperative and postoperative area with clinical symptoms. Spine 22:1990-1995. doi:10.1097/ 00007632-199709010-00009

25. Houten JK, Cooper PR (2003) Laminectomy and posterior cervical plating for multilevel cervical spondylotic myelopathy and ossification of the posterior longitudinal ligament: effects on cervical alignment, spinal cord compression, and neurological outcome. Neurosurgery 52:1081-1087 discussion 1087-1088

26. Iencean SM (2007) Alternating cervical laminoplasty for cervical spondylotic myelopathy. J Bone Joint Surg Ser B 89:639-641. doi:10.1302/0301-620X.89B5.18698

27. Igarashi K, Shibuya S, Sano H, Takahashi M, Satomi K, Ohki Y (2011) Functional assessment of proximal arm muscles by target-reaching movements in patients with cervical myelopathy. Spine J 11:270-280. doi:10.1016/j.spinee.2011.02.003

28. Iwasaki M, Okuda S, Miyauchi A, Sakaura H, Mukai Y, Yonenobu K, Yoshikawa H (2007) Surgical strategy for cervical myelopathy due to ossification of the posterior longitudinal ligament: Part 1: Clinical results and limitations of laminoplasty. Spine 32:647-653. doi:10.1097/01.brs.0000257560.91147.86

29. Iwasaki M, Kawaguchi Y, Kimura T, Yonenobu K (2002) Longterm results of expansive laminoplasty for ossification of the posterior longitudinal ligament of the cervical spine: more than 10 years follow-up. J Neurosurg 96:180-189

30. Kawaguchi Y, Matsui H, Ishihara H, Gejo R, Yasuda T (2000) Surgical outcome of cervical expansive laminoplasty in patients with diabetes mellitus. Spine 25:551-555

31. Kim YJ, Oh SH, Yi HJ, Kim YS, Ko Y, Oh SJ (2007) Myelopathy caused by soft cervical disc herniation: Surgical results and prognostic factors. J Korean Neurosurg Soc 42:441-445. doi:10.3340/jkns.2007.42.6.441

32. Kumar VG, Rea GL, Mervis LJ, McGregor JM (1999) Cervical spondylotic myelopathy: functional and radiographic long-term outcome after laminectomy and posterior fusion. Neurosurgery 44:771-777 discussion 777-778

33. Lee TT, Manzano GR, Green BA (1997) Modified open-door cervical expansive laminoplasty for spondylotic myelopathy: operative technique, outcome, and predictors for gait improvement. J Neurosurg 86:64-68

34. Magnaes B, Hauge T (1980) Surgery for myelopathy in cervical spondylosis: safety measures and preoperative factors related to outcome. Spine 5:211-214

35. Matsuda Y, Shibata T, Oki S, Kawatani Y, Mashima N, Oishi H (1999) Outcomes of surgical treatment for cervical myelopathy in patients more than 75 years of age. Spine 24:529-534. doi: 10.1097/00007632-199903150-00005 
36. Matsuoka T, Yamaura I, Kurosa Y, Nakai O, Shindo S, Shinomiya K (2001) Long-term results of the anterior floating method for cervical myelopathy caused by ossification of the posterior longitudinal ligament. Spine 26:241-248. doi:10.1097/ 00007632-200102010-00008

37. Moussa AH, Nitta M, Symon L (1983) The results of anterior cervical fusion in cervical spondylosis. Review of 125 cases. Acta Neurochir (Wien) 68:277-288

38. Naderi S, Ozgen S, Pamir MN, Ozek MM, Erzen C (1998) Cervical spondylotic myelopathy: surgical results and factors affecting prognosis. Neurosurgery $43: 43-50$

39. Naderi S, Alberstone CD, Rupp FW, Benzel EC, Baldwin NG (1996) Cervical spondylotic myelopathy treated with corpectomy: technique and results in 44 patients. Neurosurg 1:e5; discussion $1 \mathrm{p}$ following e5

40. Naruse T, Yanase M, Takahashi H, Horie Y, Ito M, Imaizumi T, Oguri K, Matsuyama Y (2009) Prediction of clinical results of laminoplasty for cervical myelopathy focusing on spinal cord motion in intraoperative ultrasonography and postoperative magnetic resonance imaging. Spine 34:2634-2641. doi:10.1097/ BRS.0b013e3181b46c00

41. Phillips DG (1973) Surgical treatment of myelopathy with cervical spondylosis. J Neurol Neurosurg Psychiatry 36:879-884

42. Ryu J-S, Chae J-W, Cho W-J, Chang H, Moon M-S, Kim S-S (2010) Cervical myelopathy due to single level prolapsed disc and spondylosis: a comparative study on outcome between two groups. Int Orthop 34:1011-1015

43. Saunders RL, Bernini PM, Shirreffs TG Jr, Reeves AG (1991) Central corpectomy for cervical spondylotic myelopathy: a consecutive series with long-term follow-up evaluation. J Neurosurg 74:163-170

44. Scardino FB, Rocha LP, Barcelos ACES, Rotta JM, Botelho RV (2010) Is there a benefit to operating on patients (bedridden or in wheelchairs) with advanced stage cervical spondylotic myelopathy? Eur Spine J 19:699-705. doi:10.1007/s00586-0091267-3

45. Sinha S, Jagetia A (2011) Bilateral open-door expansive laminoplasty using unilateral posterior midline approach with preservation of posterior supporting elements for management of cervical myelopathy and radiculomyelopathy - Analysis of clinical and radiological outcome and surgical technique. Acta Neurochir (Wien) 153:975-984. doi:10.1007/s00701-0100872-6

46. Wang MY, Green BA (2003) Laminoplasty for the treatment of failed anterior cervical spine surgery. Neurosurg 15:E7

47. Wang MY, Shah S, Green BA (2004) Clinical outcomes following cervical laminoplasty for 204 patients with cervical spondylotic myelopathy. Surg Neurol 62:487-492 discussion 492-483

48. Yamazaki T, Yanaka K, Sato H, Uemura K, Tsukada A, Nose T, Cooper PR, Sonntag VKH (2003) Cervical spondylotic myelopathy: surgical results and factors affecting outcome with special reference to age differences. Neurosurgery 52:122-126

49. Sunago K (1982) Long-term follow-up results of cervical spondylotic myelopathy-more than 5 years post-operatively-. Nihon Geka Hokan 51:995-1024

50. Alafifi T, Kern R, Fehlings M (2007) Clinical and MRI predictors of outcome after surgical intervention for cervical spondylotic myelopathy. J Neuroimaging 17:315-322. doi: 10.1111/j.1552-6569.2007.00119.x

51. Chen Y, Guo Y, Chen D, Wang X, Lu X, Yuan W (2009) Longterm outcome of laminectomy and instrumented fusion for cervical ossification of the posterior longitudinal ligament. Int Orthop 33:1075-1080. doi:10.1007/s00264-008-0609-9

52. Chen CJ, Lyu RK, Lee ST, Wong YC, Wang LJ (2001) Intramedullary high signal intensity on $\mathrm{T} 2$-weighted MR images in cervical spondylotic myelopathy: prediction of prognosis with type of intensity. Radiology 221:789-794

53. Choi S, Lee S-H, Lee J-Y, Choi WG, Choi W-C, Choi G, Jung B, Lee SC (2005) Factors affecting prognosis of patients who underwent corpectomy and fusion for treatment of cervical ossification of the posterior longitudinal ligament: analysis of 47 patients. J Spinal Disord Tech 18:309-314

54. Chung SS, Lee CS, Chung KH (2002) Factors affecting the surgical results of expansive laminoplasty for cervical spondylotic myelopathy. Int Orthop 26:334-338

55. Emery SE, Bohlman HH, Bolesta MJ, Jones PK (1998) Anterior cervical decompression and arthrodesis for the treatment of cervical spondylotic myelopathy. Two to seventeen-year followup. J Bone Joint Surg Am 80:941-951

56. Fujimura Y, Nishi Y, Chiba K, Nakamura M, Hirabayashi K (1998) Multiple regression analysis of the factors influencing the results of expansive open-door laminoplasty for cervical myelopathy due to ossification of the posterior longitudinal ligament. Arch Orthop Trauma Surg 117:471-474

57. Guidetti B, Fortuna A (1969) Long-term results of surgical treatment of myelopathy due to cervical spondylosis. J Neurosurg 30:714-721

58. Hamanishi C, Tanaka S (1996) Bilateral multilevel laminectomy with or without posterolateral fusion for cervical spondylotic myelopathy: relationship to type of onset and time until operation. J Neurosurg 85:447-451

59. Handa Y, Kubota T, Ishii H, Sato K, Tsuchida A, Arai Y (2002) Evaluation of prognostic factors and clinical outcome in elderly patients in whom expansive laminoplasty is performed for cervical myelopathy due to multisegmental spondylotic canal stenosis. A retrospective comparison with younger patients. J Neurosurg 96:173-179

60. Heidecke V, Rainov NG, Marx T, Burkert W (2000) Outcome in Cloward anterior fusion for degenerative cervical spinal disease. Acta Neurochir (Wien) 142:283-291

61. Holly LT, Moftakhar P, Khoo LT, Shamie AN, Wang JC (2008) Surgical outcomes of elderly patients with cervical spondylotic myelopathy. Surg Neurol 69:233-240. doi:10.1016/j.surneu. 2007.09.036

62. Huang RC, Girardi FP, Poynton AR, Cammisa FP Jr (2003) Treatment of multilevel cervical spondylotic myeloradiculopathy with posterior decompression and fusion with lateral mass plate fixation and local bone graft. J Spinal Disorders Tech 16:123-129

63. Hukuda S, Mochizuki T, Ogata M, Shichikawa K, Shimomura Y (1985) Operations for cervical spondylotic myelopathy. A comparison of the results of anterior and posterior procedures. J Bone Joint Surg Br 67:609-615

64. Kadanka Z, Mares M, Bednarik J, Smrcka V, Krbec M, Chaloupka R, Dusek L (2005) Predictive factors for spondylotic cervical myelopathy treated conservatively or surgically. Eur J Neurol Off J Eur Fed Neurol Soc 12:55-63

65. Kato Y, Iwasaki M, Fuji T, Yonenobu K, Ochi T (1998) Longterm follow-up results of laminectomy for cervical myelopathy caused by ossification of the posterior longitudinal ligament. J Neurosurg 89:217-223

66. Kawaguchi Y, Kanamori M, Ishihara H, Ohmori K, Abe Y, Kimura T (2003) Pathomechanism of myelopathy and surgical results of laminoplasty in elderly patients with cervical spondylosis. Spine 28:2209-2214

67. Kiris T, Kilincer C (2008) Cervical spondylotic myelopathy treated by oblique corpectomy: a prospective study. Neurosurgery 62:674-681. doi:10.1227/01.neu.0000317316.56235.a7

68. Koc RK, Menku A, Akdemir H, Tucer B, Kurtsoy A, Oktem IS (2004) Cervical spondylotic myelopathy and radiculopathy treated by oblique corpectomies without fusion. Neurosurg Rev 27:252-258. doi:10.1007/s10143-004-0342-9 
69. Koyanagi T, Hirabayashi K, Satomi K, Toyama Y, Fujimura Y (1993) Predictability of operative results of cervical compression myelopathy based on preoperative computed tomographic myelography. Spine 18:1958-1963

70. Lu J, Wu X, Li Y, Kong X (2008) Surgical results of anterior corpectomy in the aged patients with cervical myelopathy. Eur Spine J 17:129-135. doi:10.1007/s00586-007-0518-4

71. Lyu RK, Tang LM, Chen CJ, Chen CM, Chang HS, Wu YR (2004) The use of evoked potentials for clinical correlation and surgical outcome in cervical spondylotic myelopathy with intramedullary high signal intensity on MRI. J Neurol Neurosurg Psychiatry 75:256-261

72. Masaki Y, Yamazaki M, Okawa A, Aramomi M, Hashimoto M, Koda M, Mochizuki M, Moriya H (2007) An analysis of factors causing poor surgical outcome in patients with cervical myelopathy due to ossification of the posterior longitudinal ligament: anterior decompression with spinal fusion versus laminoplasty. J Spinal Disorders Tech 20:7-13. doi:10.1097/01.bsd.000021 1260.28497.35

73. Mastronardi L, Elsawaf A, Roperto R, Bozzao A, Caroli M, Ferrante M, Ferrante L (2007) Prognostic relevance of the postoperative evolution of intramedullary spinal cord changes in signal intensity on magnetic resonance imaging after anterior decompression for cervical spondylotic myelopathy. J Neurosurg Spine 7:615-622. doi:10.3171/SPI-07/12/615

74. Nagashima H, Morio Y, Yamashita H, Yamane K, Teshima R (2006) Clinical features and surgical outcomes of cervical myelopathy in the elderly. Clin Orthop Rel Res 140-145. doi: 10.1097/01.blo.0000201156.21701.86

75. Nagata K, Ohashi T, Abe J, Morita M, Inoue A (1996) Cervical myelopathy in elderly patients: clinical results and MRI findings before and after decompression surgery. Spinal Cord 34:220-226

76. Ogawa Y, Toyama Y, Chiba K, Matsumoto M, Nakamura M, Takaishi H, Hirabayashi H, Hirabayashi K (2004) Long-term results of expansive open-door laminoplasty for ossification of the posterior longitudinal ligament of the cervical spine. J Neurosurg Spine 1:168-174

77. Okada Y, Ikata T, Yamada H, Sakamoto R, Katoh S (1993) Magnetic resonance imaging study on the results of surgery for cervical compression myelopathy. Spine 18:2024-2029

78. Park Y-S, Nakase H, Kawaguchi S, Sakaki T, Nikaido Y, Morimoto T (2006) Predictors of outcome of surgery for cervical compressive myelopathy: retrospective analysis and prospective study. Neurol Med Chir (Tokyo) 46:231-238 discussion 238-239

79. Satomi K, Ogawa J, Ishii Y, Hirabayashi K (2001) Short-term complications and long-term results of expansive open-door laminoplasty for cervical stenotic myelopathy. Spine J 1:26-30

80. Singh A, Choi D, Crockard A (2009) Use of walking data in assessing operative results for cervical spondylotic myelopathy: Long-term follow-up and comparison with controls. Spine 34:1296-1300. doi:10.1097/BRS.0b013e3181a09796

81. Singh A, Crockard HA, Platts A, Stevens J (2001) Clinical and radiological correlates of severity and surgery-related outcome in cervical spondylosis. J Neurosurg 94:189-198

82. Uchida K, Nakajima $H$, Sato R, Kokubo Y, Yayama $T$, Kobayashi S, Baba H (2005) Multivariate analysis of the neurological outcome of surgery for cervical compressive myelopathy. J Orthop Sci 10:564-573. doi:10.1007/s00776-005-0953-1

83. Wada E, Yonenobu K, Suzuki S, Kanazawa A, Ochi T (1999) Can intramedullary signal change on magnetic resonance imaging predict surgical outcome in cervical spondylotic myelopathy? Spine 24:455-462. doi:10.1097/00007632-19990301000009

84. Wiberg J (1986) Effects of surgery on cervical spondylotic myelopathy. Acta Neurochir (Wien) 81:113-117
85. Wohlert L, Buhl M, Eriksen EF, Fode K, Klaerke A, Kroyer L, Lindeberg H, Madsen CB, Strange P, Espersen JO (1984) Treatment of cervical disc disease using Cloward's technique. III. Evaluation of cervical spondylotic myelopathy in 138 cases. Acta Neurochir (Wien) 71:121-131

86. Hirai O, Kondo A, Aoyama I, Nin K (1991) Anterior decompression surgery of aged patients with cervical myelopathy. No Shinkei Geka 19:1017-1023

87. Fujiwara K (1987) Study of factors related to the surgical prognosis of cervical compression myelopathy. Nihon Seikeigeka Gakkai Zasshi 61:143-154

88. Cheng S-C, Yen C-H, Kwok TK, Wong W-C, Mak K-H (2009) Anterior spinal fusion versus laminoplasty for cervical spondylotic myelopathy: a retrospective review. J Orthop Surg (Hong Kong) 17:265-268

89. Chibbaro S, Benvenuti L, Carnesecchi S, Marsella M, Pulera F, Serino D, Gagliardi R (2006) Anterior cervical corpectomy for cervical spondylotic myelopathy: experience and surgical results in a series of 70 consecutive patients. J Clin Neurosci 13:233-238. doi:10.1016/j.jocn.2005.04.011

90. Ebersold MJ, Pare MC, Quast LM (1995) Surgical treatment for cervical spondylitic myelopathy. J Neurosurg 82:745-751

91. Furlan JC, Kalsi-Ryan S, Kailaya-Vasan A, Massicotte EM, Fehlings MG (2011) Functional and clinical outcomes following surgical treatment in patients with cervical spondylotic myelopathy: A prospective study of 81 cases. J Neurosurg Spine 14:348-355. doi:10.3171/2010.10.SPINE091029

92. Hasegawa K, Homma T, Chiba Y, Hirano T, Watanabe K, Yamazaki A (2002) Effects of surgical treatment for cervical spondylotic myelopathy in patients $>$ or $=70$ years of age: a retrospective comparative study. J Spinal Disord Tech $15: 458-460$

93. Kim HJ, Moon SH, Kim HS, Moon ES, Chun HJ, Jung M, Lee HM (2008) Diabetes and smoking as prognostic factors after cervical laminoplasty. J Bone Joint Surg Ser B 90:1468-1472. doi:10.1302/0301-620X.90B11.20632

94. King JT Jr, Moossy JJ, Tsevat J, Roberts MS (2005) Multimodal assessment after surgery for cervical spondylotic myelopathy. J Neurosurg Spine 2:526-534

95. Morio Y, Teshima R, Nagashima H, Nawata K, Yamasaki D, Nanjo Y (2001) Correlation between operative outcomes of cervical compression myelopathy and MRI of the spinal cord. Spine 26:1238-1245. doi:10.1097/00007632-200106010-00012

96. Nagashima H, Dokai T, Hashiguchi H, Ishii H, Kameyama Y, Katae Y, Morio Y, Morishita T, Murata M, Nanjo Y, Takahashi T, Tanida A, Tanishima S, Yamane K, Teshima R (2011) Clinical features and surgical outcomes of cervical spondylotic myelopathy in patients aged 80 years or older: a multi-center retrospective study. Eur Spine J 20:240-246

97. Rajshekhar V, Kumar GSS (2005) Functional outcome after central corpectomy in poor-grade patients with cervical spondylotic myelopathy or ossified posterior longitudinal ligament. Neurosurgery 56:1279-1284 (discussion 1284-1275)

98. Shin JJ, Jin BH, Kim KS, Cho YE, Cho WH (2010) Intramedullary high signal intensity and neurological status as prognostic factors in cervical spondylotic myelopathy. Acta Neurochir (Wien) 152:1687-1694. doi:10.1007/s00701-010-0692-8

99. Suri A, Chabbra RPS, Mehta VS, Gaikwad S, Pandey RM (2003) Effect of intramedullary signal changes on the surgical outcome of patients with cervical spondylotic myelopathy. Spine J 3:33-45

100. Suzuki A, Misawa H, Simogata M, Tsutsumimoto T, Takaoka K, Nakamura H (2009) Recovery process following cervical laminoplasty in patients with cervical compression myelopathy: prospective cohort study. Spine 34:2874-2879. doi:10.1097/ BRS.0b013e3181bb0e33 
101. Tanaka J, Seki N, Tokimura F, Doi K, Inoue S (1999) Operative results of canal-expansive laminoplasty for cervical spondylotic myelopathy in elderly patients. Spine 24:23082312

102. Zhang Y-Z, Shen Y, Wang L-F, Ding W-Y, Xu J-X, He J (2010) Magnetic resonance T2 image signal intensity ratio and clinical manifestation predict prognosis after surgical intervention for cervical spondylotic myelopathy. Spine 35:E396-E399

103. Zhang P, Shen Y, Zhang Y-Z, Ding W-Y, Wang L-F (2011) Significance of increased signal intensity on MRI in prognosis after surgical intervention for cervical spondylotic myelopathy. J Clin Neurosci 18:1080-1083

104. Vitzthum HE, Dalitz K (2007) Analysis of five specific scores for cervical spondylogenic myelopathy. Eur Spine J 16:20962103. doi:10.1007/s00586-007-0512-x

105. Yonenobu K, Abumi K, Nagata K, Taketomi E, Ueyama K (2001) Interobserver and intraobserver reliability of the japanese orthopaedic association scoring system for evaluation of cervical compression myelopathy. Spine (Phila Pa 1976) 26:1890-1894 (discussion 1895) 